Cahiers $d u$ MONDE RUSSE

\section{Cahiers du monde russe}

Russie - Empire russe - Union soviétique et États indépendants

$46 / 1-2$ | 2005

La Russie vers 1550

\title{
Limites et portée du comparatisme
}

\section{André Berelowitch}

\section{OpenEdition \\ Journals}

Édition électronique

URL : https://journals.openedition.org/monderusse/2714

DOI : 10.4000/monderusse. 2714

ISSN : $1777-5388$

\section{Éditeur}

Éditions de l'EHESS

Édition imprimée

Date de publication : 1 janvier 2005

Pagination : 13-18

ISBN : 2-7132-2055-6

ISSN : $1252-6576$

Référence électronique

André Berelowitch, «Limites et portée du comparatisme », Cahiers du monde russe [En ligne], 46/1-2 | 2005, mis en ligne le 06 janvier 2014, consulté le 04 septembre 2022. URL : http://

journals.openedition.org/monderusse/2714; DOI : https://doi.org/10.4000/monderusse.2714 


\section{ANDRÉ BERELOWITCH}

\section{LIMITES ET PORTÉE DU COMPARATISME}

\section{On ne peut pas comparer un pou et un cheval. Paul Reboux et Charles Muller}

Le thème proposé aux participants, venus pour moitié de Russie, pour moitié d'autres pays d'Europe, du séminaire doctoral de septembre 2003 (nom de code : «Drerupa $»^{1}$ ) était simple en apparence, et même canonique : « Naissance d'une monarchie nationale et formation d'un État russe (milieu du XIVe - milieu du $\mathrm{XVI}^{\mathrm{e}}$ siècle) dans le contexte européen ». En réalité, il soulevait une série de questions plus complexes les unes que les autres. La Russie du XVI ${ }^{\mathrm{e}}$ siècle est-elle, à proprement parler, un État, même si l'on prend soin d'ajouter « archaïque » ? Peuton parler d'État, en Europe occidentale ou ailleurs, avant le XVIII ${ }^{\mathrm{e}}$ siècle, voire le $\mathrm{XIX}^{\mathrm{e}}$ siècle ${ }^{2}$ ? Évitons donc d'employer ce terme controversé : l'entité politique qui se désigne elle-même par l'expression Moskovskoe gosudarstvo (les contemporains traduisaient «Moscovie ») est-elle bien « nationale » dans le sens que nous donnons à ce mot? Multiethnique, multiconfessionnelle, est-elle vraiment semblable à l'Angleterre, à l'Espagne (sans l'empire colonial), à la France de son époque ? La conquête, au milieu du XVIe siècle précisément, des khanats de Kazan, puis d'Astrakhan, n'est-elle pas un premier pas vers l'empire ? Les quatre derniers mots du titre, enfin, délibérément ambigus, semblaient annoncer une étude comparative entre la Russie et les puissances d'Europe centrale et occidentale, exercice maintes fois tenté, mais jamais de façon systématique et avec un succès généralement médiocre ${ }^{3}$.

1. Premières syllabes du russe Drevnjaja Rus` Pariž, « Ancienne Russie Paris ».

2. Voir ci-dessous l'article de J.-F. Schaub

3. Avec au moins une exception : le bref article de S. M. Kaštanov, « O tipe russkogo gosudarstva v 14-16 vv. » [«Type d'État en Russie aux XIVe-XVI siècles »], in Čtenija pamjati V. B. Kobrina. Problemy otečestvennoj istorii i kul'tury perioda feodalizma [Conférence à la mémoire de V. B. Kobrin. Autour de l'histoire et de la culture de la Russie à l'époque du féodalisme], Moscou, 1992, p. 85-92. 
Comme dans tout rassemblement d'historiens qui se respecte, on a surtout parlé d'autre chose. Maureen Perrie est la seule qui ait abordé de front le problème crucial : la monarchie russe est-elle « nationale », « populaire », « démocratique » ... ou rien de tout cela? Anton Gorskij, Bulat Rahimzjanov et Elena Rusina ont replacé la Moscovie dans le contexte de l'Europe orientale. Pavel Čečenkov, Irina Man'kova ont évoqué les méthodes employées par Moscou pour assimiler les nouveaux territoires. Mihail Krom et Angela Rustemeyer ont comparé l'institution de la régence et la répression du crime de lèse-majesté en Russie avec ce qui se pratiquait dans d'autres pays d'Europe. Valerie Kivelson a expliqué, de façon convaincante, pourquoi les historiens américains (mais sont-ils bien les seuls ?) parlent d'autre chose : ils ont abandonné l'histoire politique et institutionnelle pour explorer les profondeurs de la société, sa «culture » politique, juridique, religieuse, voire (mais bien plus rarement) économique.

Il y a quarante ou quarante-cinq ans, une rencontre aussi prolongée, aussi franche et informelle entre historiens russes et non russes n'aurait pu avoir lieu. Si elle s'était tenue quand même, nous aurions assisté au choc des idéologies (qui ne se souvient, parmi les modernistes de ma génération, des duels épiques Roland Mousnier-Boris Porchnev ?) Chacun aurait cherché à persuader l'autre de la supériorité de ses méthodes et de sa conception de l'histoire. On aurait argumenté à perte de vue sur la nature de l'État, proto-féodal, féodal ou féodal avancé, sur le rôle des classes sociales, sur le caractère progressiste ou rétrograde des guerres ou des réformes.

Rien de tel en 2003. Personne n'a cherché à évaluer (ou à nier) le retard de la Russie sur l'Europe occidentale. Personne ne s'est préoccupé de retracer, en toile de fond, l'expansion de la principauté de Moscou ou l'évolution de ses institutions. La confrontation entre les trois historiographies représentées (historiens russes de la Russie, occidentaux de l'Europe occidentale et historiens occidentaux de la Russie) - un des principaux objectifs du séminaire - n'a donné lieu à aucun exposé théorique ; on s'est contenté d'une simple juxtaposition. De même, la joute entre l'histoire érudite, héritière de l' « histoire et philologie » du XIX siècle, qui constituait naguère encore la Bible des médiévistes russes, et l'histoire interprétative, puisant à pleines mains dans les ressources des autres sciences humaines, que l'on a pris la fâcheuse habitude, en Russie notamment, d'appeler «l'école des Annales ». De même encore, les comparaisons entre la Russie et la France, l'Angleterre, l'Empire. À chaque fois, on a procédé par petites touches. Finies, les grandes fresques historiques: l'impressionnisme triomphe. Ce changement complet d'atmosphère, dont l'écroulement du régime soviétique n'est que très partiellement responsable, nous présente une petite énigme que je tenterai d'éclaircir dans les quelques pages qui suivent, en partie pour ma propre satisfaction, en partie pour la lumière que sa solution pourrait apporter sur la nature et les enjeux de la nouvelle histoire en train de s'écrire.

J'aborderai le problème par un biais, en essayant de répondre à la question : pourquoi la comparaison, qui semble connaître un regain de popularité sous le nom d' « histoire croisée », est-elle devenue si difficile ? Laissant de côté les subtilités 
techniques les plus abstruses ${ }^{4}$, je me contenterai de soumettre à ce que j'appellerai une critique structuraliste simple, c'est-à-dire datant des années 1970, les deux types de raisonnement les plus courants, employés par l'historien de façon presque machinale. Lorsque l'on constate des similitudes frappantes entre deux sociétés si éloignées dans l'espace ou le temps que toute possibilité d'emprunt est exclue d'emblée, on invoquera l'adage « les mêmes causes produisent les mêmes effets ». L'explication, pour plausible qu'elle soit, n'est valide que si les causes en question agissent au sein de milieux identiques. Or nous savons bien que toutes les sociétés humaines diffèrent les unes des autres comme le font des organismes vivants, qu'ils appartiennent ou non à la même espèce. Les conditions matérielles, économiques, sociales ont beau être semblables, l'expérience vécue par les différents groupes humains est à chaque fois singulière ; un même événement sera réfracté, à chaque fois, par une mémoire, une conscience collective qu'on ne saurait confondre avec aucune autre.

Supposons, à l'inverse, que l'emprunt soit envisageable, voire prouvé. L'ancien « diffusionnisme », qui garde plus d'adeptes qu'on ne croit, s'estimait heureux s'il avait retrouvé l'origine du phénomène. Nous savons maintenant que l'historien doit encore resituer l'échange dans la configuration sociale du point d'origine et dans celle du point d'arrivée : comprendre les raisons du prêteur comme de l'emprunteur, la réception du message par celui-ci et l'influence en retour subie par celui-làs

Comment, si l'on entend satisfaire à ces exigences de rigueur, pourrait-on comparer de façon globale une société à une autre, par exemple la Russie du XVII ${ }^{\mathrm{e}}$ siècle à l'empire carolingien ? Le développement historique de l'Afrique à celui de l'Asie ? Les rapprochements oscillent entre deux pôles également critiquables, les perspectives si vastes qu'elles en sont nébuleuses et les coïncidences ponctuelles, dont la seule utilité apparente est de rappeler que la société étudiée n'est pas la seule sur la planète, contrairement à ce que ses historiens auraient tendance à s'imaginer ${ }^{6}$.

Confronté à un problème qu'on pourrait à bon droit considérer comme essentiel à sa discipline (jalonner le devenir des sociétés humaines), l'historien comparatiste se retrouve dans la situation d'un mathématicien qui devrait classer deux nombres appartenant à des ensembles ordonnés différents, d'un paléontologiste qui aurait affaire à des animaux fossiles dont chacun constitue un ordre à lui tout seul. Aucune

4. Cf. Michael Werner, Bénédicte Zimmermann, «Penser l'histoire croisée : entre empirie et réflexivité », Le genre humain, 42, 2004, p. 15-41 (Numéro thématique intitulé : « De la comparaison à l'histoire croisée »).

5. La porcelaine manufacturée en Chine au XVIII siècle à l'intention des importateurs européens, décorée de façon plus chinoise que nature pour se conformer à leur goût, offre un exemple de ce genre de chassé-croisé.

6. Bien que coupable, l'auteur du présent article (cf. La hiérarchie des égaux, Paris, 2001, p. 180 et passim) n'est pas seul sur le banc des accusés : voir par exemple Michael Cherniavsky, « Ivan the Terrible as Renaissance Prince », Slavic Review, 27, 1968, p. 195-211 ; Daniel B. Rowland, «Ivan the Terrible as a Carolingian Renaissance Prince », Harvard Ukrainian Studies, XIX, 1995, p. 594-606 ; Charles J. Halperin, « Ivan IV and Chinggis Khan », Jahrbücher für Geschichte Osteuropas, Neue Folge, 51 :4, 2003, p. 481-497. 
comparaison tant soit peu approfondie n'est possible sans un cadre de référence, et c'est justement ce qui lui fait défaut.

L'histoire positiviste, telle qu'elle s'est constituée dans la seconde moitié du $\mathrm{XIX}^{\mathrm{e}}$ siècle, s'interdisait, par définition, toute théorie générale, mais non pas toute comparaison. La foi dans le progrès la protégeait de l'agnosticisme véritable. Sur la courbe approximativement ascendante qui représentait l'évolution de l'humanité, elle se refusait à placer des «plus » et des «moins », mais ne pouvait s'empêcher de donner à l'avant et à l'après une signification plus que chronologique.

L'histoire pseudo-marxiste du XX $\mathrm{X}^{\mathrm{e}}$ siècle, qui partageait sans s'en rendre compte les croyances naïves de son adversaire « bourgeois », avait renchéri en disposant, sur l'axe jusque-là indifférencié du temps, des points de repère. Toute société portait en elle une loi universelle de développement qui, à travers les luttes de classes, les famines et les guerres, la poussait infailliblement en avant. Sa vitesse pouvait varier, ainsi que la durée des arrêts à chaque gare ; mais la locomotive de l'histoire, pour aller de la communauté primitive au socialisme, devait passer par l'esclavage, le système féodal et le capitalisme ${ }^{7}$.

Le «matérialisme historique » fut le premier à disparaître, nous laissant le marxisme vivant, c'est-à-dire un faisceau d'hypothèses fécondes à critiquer et à vérifier. Instruments de recherche, elles ne sauraient remplacer cette théorie générale de l'histoire que nous avions cru, à tort, posséder. La foi dans le progrès s'est effritée, et si les méthodes positivistes ont fait leurs preuves, elles sont incapables d'éclairer la route de l'historien. Les faits sociaux, qu'ils relèvent de l'histoire ou des autres sciences humaines, nous apparaissent comme les pièces d'un puzzle que nous ne savons pas assembler.

C'est en se modelant sur ce puzzle, en s'adaptant avec pragmatisme à son aspect fragmentaire qu'est née la cultural history américaine, particulièrement active dans le domaine russe. Personne ne songe à nier la richesse de ses apports, tant sur le plan de la méthode que sur celui des faits. Elle a su pénétrer derrière les façades, trop souvent artificielles, il faut bien le reconnaître, qu'avaient érigées les historiens des institutions. Véritable ethnographe du passé, elle a cherché à reconstituer les comportements et les façons de penser des acteurs de l'histoire. Sensible avant tout à la cohérence interne d'un groupe humain, s'adaptant avec souplesse à son idiome, elle a traité chaque société comme une « culture » distincte, les états successifs de cette société pouvant, selon l'importance des changements, être considérés comme autant de cultures distinctes, ou comme des sous-cultures rattachées à la culture principale. Mais les adeptes de cette nouvelle histoire ne prennent pas garde que, ce faisant, ils traitent chaque société étudiée comme une nature, dont sa seule existence suffit à rendre compte. Loin d'expliquer les singularités qu'ils rencontrent par leurs causes, ils les figent dans leur état de singularités, puisqu'elles expriment selon eux une culture particulière et ne résultent pas du jeu de lois universelles qui s'appliqueraient à l'ensemble du genre humain. Comme ils privilégient la solidarité horizontale des structures, ils sont incapables de concevoir, à plus forte raison

7. Cf. Louis Althusser, Pour Marx, Paris, 1965. 
d'expliquer, leurs changements : l'histoire culturelle est une histoire statique. Comme enfin chaque groupe humain est enfermé dans sa culture, l'histoire globale du monde disparaît comme telle, et avec elle le « tragique » de l'histoire (Raymond Aron) : y aurait-il donc une « culture » totalitaire ?

S'il en est ainsi, si l'histoire indifférenciée des cultures est une « nuit où toutes les vaches sont grises », si nous avons renoncé à la théorie pseudo-marxiste (le crépuscule où toutes les vaches vont en rangs par deux) et ne l'avons remplacée par aucune autre, cela veut dire que désormais nous ne comparons plus entre elles des grandeurs connues, avec des résultats prévisibles, mais que nous établissons des rapports entre des matériaux hétérogènes, avec des résultats imprévisibles. Si un rituel, une coutume, un détail de l'organisation politique d'une société A évoque un trait correspondant d'une société $\mathrm{B}$ située à des années-lumière de la première ${ }^{8}$, nous ne pouvons plus récuser le rapprochement sous prétexte d'invraisemblance, car nous ne savons pas, littéralement pas, ce que sont les sociétés humaines. À plus forte raison ne savons-nous pas les classer.

Dès lors, la comparaison cesse d'être cet exercice relativement bénin, sorte de jeu d'esprit ou de divertissement érudit autorisant le pittoresque, qui délassait, le temps d'un article, les historiens sérieux. Elle devient un moyen d'exploration, un des plus puissants et des plus féconds qui soient, si on l'utilise avec toute la rigueur désirable. Elle met en jeu toutes les sciences sociales et humaines, car de même que la multiplicité des visées restitue l'épaisseur de l'objet, c'est précisément la diversité des approches qui confère au fait social sa substance. Celui-ci ne peut être saisi et interprété qu'à travers des chaînes virtuellement infinies de comparaisons ou de mises en rapport, auxquelles ni l'espace, ni le temps, et encore moins les fragiles cloisons entre les disciplines, ne sauraient imposer de limites.

On comprend l'embarras de l'historien devant ce comparatisme généralisé qui le menace et qui déjà envahit sournoisement sa pratique quotidienne. Un embarras qui a toutes chances de durer, car les causes profondes qui ont fait voler en éclats une vision du monde vieille de plusieurs siècles n'ont pas fini d'agir : elles ne font probablement que commencer. Mais ce que l'historien perd en certitude, il le gagne en curiosité.

IVe Section de l'École pratique des hautes études

Paris

andre.berelowitch@wanadoo.fr

8. Ainsi, Vladimir Propp, dans les Racines historiques du conte de fées, interprète l'ogre occidental, qui «sent la chair fraîche » à travers les aventures d'un Orphée amérindien du NordOuest, que les esprits découvrent parmi les cadavres. Furieux, ils s'écrient : «Il pue ! Il n'est pas mort!». 
